\title{
A Comparative Study on South African Users' Perception to Use, Choose, and Purchase a Smartphone Device through the Lens of the Social Shaping of Technology (SST) Theory
}

\author{
Lufungula Osembe \\ Faculty of Information Communication and Technology \\ Independent Institute of Education-Rosebank College \\ Johannesburg, South Africa \\ Email: losembe [AT] rosebankcollege.co.za
}

\begin{abstract}
Mobile technologies are increasingly making important contributions to the lives of many users. Various factors are said to influence the decision of users to remain connected and be in constant interaction with other users from the same or different social networks. This paper used the Social Shaping of Technology (SST) theory to assess the influence of users' social networks on their decision to use, choose and purchase a smartphone device. The study used a quantitative research method to analyse data. Data were collected from a sample of young adults aged between 15 and 35 years residing in Durban, South Africa. The study revealed that social networking sites influence users' decision to use, choose, and purchase a smartphone device. The findings also revealed factors that are perceived as influential in the perceptions of users about their social networks and their interactions with users from the same social networks.
\end{abstract}

Keywords-Mobile communication; mobile technology device; smartphone device; socio-networking sites; social shaping technology; social capital; social influence; perceived mobility value; social networks

\section{INTRODUCTION}

Mobile technologies play an important role in shaping the lives of many users. The decision to use and purchase a mobile device is left to users, who are constantly shaped by the direction of technology and the need to remain connected in their social networks.

This study discusses the perceptions of users about their decision to use, choose, and purchase a mobile device. The study further assesses the influence of some users' perceptions on the decision of other users from the same social network to use, choose, and purchase a smartphone device.

Aspects discussed in this study are as follows: The background of the study is presented in section II, followed by the aim of the study in section III. Section IV discusses the research questions, followed by the research objectives in section $\mathrm{V}$. The literature review is presented in section VI, followed by the theoretical framework in section VII. In section VIII, the research methodology is covered. Data analysis and results are discussed in section IX, followed by suggestions and recommendations for further research, and a conclusion is presented in section $\mathrm{X}$.

\section{BACKGROUND}

To present the case about the users' social networks and their influence on the decisions to use, choose, and purchase a smartphone device, it is important to establish the context of this study. A social network is referred to as a set of individuals sharing the same interest [5]. The authors argue that individuals from the same social network are likely to benefit from each other. Smartphone devices have become an integral part of life for many users [17].

The authors claim that smartphone devices have become inseparable from users in some instances. The decision to use and purchase a smartphone device seems to be largely influenced by the environment in which users live [27]. Little is known in South Africa, especially in Durban where this study was conducted, regarding the decision of users to purchase and use a mobile communication device. This study assesses the perceptions of users about their decision to use, choose, and purchase a smartphone device in their social networks. Also, variables influencing the decision to use, choose, and purchase a smartphone device are critically analysed since they shape the perceptions of users.

To understand the phenomenon under investigation, there is a need to explain the variables used in this study. This study refers to any electronic device that can be used to communicate, such as a cell phone or smartphone, portable device, notepad, tablet, as well as a laptop, including other portable or wearable devices, as a smartphone device. For this 
study, a smartphone device will be the primary medium device since it is widely used and is available [27].

\section{A. Context of the study}

The study was conducted in Durban. Durban is the largest urban city in the South African province of KwaZuluNatal. The metropolitan city is ranked the third most populous urban city in South Africa, after Johannesburg and Cape Town.

Durban as a metropolitan area was selected because of its accessibility and its urban infrastructure. Durban is considered the third-largest South African urban city with the highest penetration of mobile communication devices and good domestic telecommunications expansion [16]. The selection of the city was also motivated by the fact that the findings of the study could be compared to the findings of a similar study conducted in St Petersburg, Russia [17].

St Petersburg is the Russian domestic telecommunication market and enjoys an economic and telecommunication expansion [17]. Both Durban and $\mathrm{St}$ Petersburg enjoy a potential growth in terms of urbanisation, hence, the interest of the researcher to use the two cities as a comparison context for this study.

This research was limited by the sample of the target population that took part in the study. The study's findings could be extended to other urban cities in South Africa to ascertain the influence of users' social networks regarding their decision to use, choose, and purchase a mobile device. The study targeted young adults residing in the Durban metropolitan area. For this study, young adults were selected as the target population. Young adults are among the largest consumer population of mobile devices in South Africa [1].

Many young adults are born digital, and with this birthright comes not only great exposure to technology but also a great love for new technologies [22].

The authors further explain that young adults tend to use smartphones beyond what they were initially designed for, and, as a result, they bring innovation in the context and process of use [22]. This study is interested in exploring the gaps identified in the literature to evaluate variables that shape the users' perception to influence the decision to use, choose, and purchase a smartphone in the social networks.

\section{AIM OF THE STUDY}

This study aims to evaluate the users' perceptions about their decision to use, choose, and purchase a smartphone device in their social networks. The literature explains that many studies have been conducted on smartphone devices; however, little has been done to evaluate the perceptions of users on the decision to use, choose, and purchase a smartphone in the context of users' social networks.

Variables used in the users' social network context have not been extensively researched to establish the extent of the influence on their perceptions and further assess how smartphones are used to connect and interact with users from the same social network, and consequently shape the decision to choose or purchase a smartphone device.

\section{RESEARCH QUESTIONS}

Research question 1: To what extent do social networks influence the decision of users to use, choose, and purchase a smartphone device?

Sub-research Q1: What are the benefits of using a smartphone device in the users' social networks?

Sub-research Q2: What are the factors that influence the decision to use, choose, and purchase a smartphone device in the users' social network?

\section{RESEARCH OBJECTIVES}

The study has the following objectives:

Research objective 1: To assess the extent of users' social networks to influence the decision to use, choose, and purchase a smartphone device.

Sub-research objective 1: To evaluate the benefits of using a smartphone device in the users' social networks.

Sub-research objective 2: To evaluate factors that influence the users' perceptions to use, choose and purchase a smartphone device in their social networks.

\section{LITERATURE REVIEW}

This section discusses the literature review. The following issues are discussed in this section, namely, (A) users' social networks and choice of smartphone devices, (B) mobile communication ownership and affordability, (C) usage of a mobile communication device, (D) users' perceptions about their service and mobile network providers, and (E) consideration variables in the purchase of a smartphone device.

\section{A. Users' Social networks and choice of smartphone devices}

Many users feel pressure from those around them to be constantly connected in the social network [22]. Also, the authors claim that users' decision to be part of a social network increases the amount of pressure and the need for responsiveness from the following groups, namely, peers, parents, employers, friends, family, to name but a few.

According to [14], the authors explain that the willingness to remain connected with its social network plays a crucial role in the decision of users to use, choose and purchase a smartphone device. This study considers the social network as a grouping of individuals by value or common interests [14].

Social networks of users influence the purchasing decision and choice of mobile devices [22]. Also, the authors explain that the users' social networks affect the selection of contract terms associated with the service providers of smartphone devices. Little is known in Durban, South Africa about the decision of users to use, choose, and purchase a 
smartphone device in their respective social networks. There is a need in this study to ascertain the effect of users' social networks and assess how they influence the decision of users to use, choose and purchase a smartphone device.

With the current development of mobile technologies, users in social networks tend to possess what any if not most peers possess, and this includes smartphone devices [17]. The decision to use, choose and purchase a smartphone device should be guided by the perceived values and benefits in the context of the users' social network [17].

\section{B. Mobile communication ownership and affordability}

After discussing the users' social networks and choice of smartphone devices, this section discusses mobile communication ownership and affordability. Affordability, accessibility, and technology innovation affect the use, choice, and purchase of smartphone devices [27]. The authors add that mobile communication influences the establishment of a strong relationship among users from the same social network [27]. The perceptions of users from the same social network about their decision to own a smartphone device need to be looked at closely in this context [28].

Users from the same social network are likely to remain connected using mobile communication technologies [28]. This raises the issue of mobile communication devices' ownership. The use of smartphone devices is based on shared access rather than on ownership [1]. Also, the authors claim that many young people, even in some poor urban areas, own a smartphone device [1].

Young people would like to own a smartphone device [1]. The authors further explain that the penetration and use of smartphone devices are substantial in South Africa as compared to the rest of the other African countries [1]. Since this study was conducted in South Africa, there is a need to understand the state of smartphone device ownership.

Young people use smartphone devices to promote social interaction and connect to families and friends [28]. Mobile communication plays an important role in social change and social cohesion [18]. The authors further argue that young adults represent one of the largest populations of consumers who own a smartphone device [18]. Little is known in the literature about the ownership of smartphone devices in Durban, South Africa.

\section{Usage of a mobile communication device}

Mobile communication brings various benefits that shape society [21]. The authors further explain that the advent of smartphone devices, with capabilities to integrate various applications and support various features to do more than one task, have played a meaningful role in the lives of many users [21].

There has been a shift in the way smartphone devices are used [27]. The authors argue that users use their mobile devices for activities such as text messaging, voice communication, mobile TV, SMS, video game, live streaming, multimedia services, application download, mobile and electronic payment, and music services [27]. The new generation of $3 \mathrm{G}, 4 \mathrm{G}$, and $5 \mathrm{G}$ smartphone devices are equipped with capabilities to function at higher speeds [31].

The authors further explain that this new generation of smartphones is well-equipped to do more than one task at a time [31]. Functions can be operated simultaneously, for example, accessing emails, message synchronisation, Internet access and browsing of social networking sites, digital photography, removable storage, Wi-Fi enabled, and GPS.

The use of smartphone devices has increased the notion of sociability, reassurance, entertainment, and time management, as well as other benefits [28]. The authors further explain that the use of smartphone devices has increased human interaction among their users [28].

The authors explain that human interaction has gone beyond simple communication and has resulted in other perceived values [28]. The use of smartphone devices has shaped the lives of users in their social network because of constant interaction through various media [27].

The authors discuss the various benefits of smartphone devices in the banking sector [16]. The authors provide examples of platforms used to transfer and receive money such as Wizzit and M-Pesa [16]. These platforms are said to bring enormous benefits to the private banking sector while delivering substantial contributions to the ordinary citizen [16].

Smartphone devices are perceived to generate economic growth and provide many opportunities for society [10]. Opportunities offered by smartphone devices are diverse in context [1]. The authors cite opportunities such as job search, trade networks, mobile banking, remittance oversight to health management, mobile learning, community development and election monitoring, to name but a few [1]. Smartphone devices have increased the capacity and reach of decentralised informal systems based on inter-individual interactions [28].

The authors discuss an important aspect of the proliferation of cultural activities associated with the use of smartphone devices [18]. The authors argue that besides the commonly used functions of smartphone devices, users have managed to perform the following such as building identity, displaying fashion, meeting new people, interacting with television programs, surfing the Internet, flirting, dating, as well as locating people [18].

These activities are performed as the need arises among users in their social networks [27]. There is little knowledge in the literature about the use of smartphone devices associated with the proliferation of cultural behaviours 
in South Africa among users from the same social network. There is a need to assess the activities that go beyond sending and receiving a text message using a smartphone device to evaluate the extent of users' perceptions on their decision to use, choose, and purchase a smartphone device in a social network.

\section{The users' perceptions about their mobile network and providers}

This section discusses the users' perceptions of their mobile network and service providers. Users have control over their decision to choose the type of smartphone device, its features, applications, as well as manufacturers [20]. Also, the authors explain that users have the option of whether they like or dislike a mobile device [20]. The authors further explain that users have a choice of whether to purchase or not to purchase a smartphone device [20].

Users have a great expectation regarding the quality of service provided by their network provider(s) [7]. The authors further argue that the quality of contract terms has the potential to improve the relationship between the service provider and the user [7]. Also, the authors claim that the quality of service has the potential to increase the level of trust between the user and the service provider, and then further instil a high level of satisfaction [7].

Users choose a smartphone device because of the benefits offered by the service providers and manufacturers such as usefulness, user control, service compatibility, ownership of risks, perceived fees, and technical costs [24].

From a technological perspective, mobile network and service providers are developing new marketing strategies to attract new users and retain old ones [27]. The authors further explain that mobile network and service providers are focused on retention strategies to convince users to buy new devices and related service offerings [27].

To influence the decision of users to purchase a smartphone device and use the service from the same provider or manufacturer, these service and mobile network providers do not need to take advantage of the social vacuum only [11].

Instead, mobile network and service providers need to consider the combination of social forces to retain old users and attract new users. The authors further argue that in some instances, mobile network and service providers need to listen to users' feedback in developing new strategies with users' needs in mind [11]. Little is known in the literature about the perceptions of users on the mobile network and service providers in Durban.

The authors further argue that the benefits and support offered by mobile network and service providers play a crucial role in customer retention [27]. Also, the authors explain that the mobile network and service providers need to focus on key drivers such as service quality, customer service and affordability to retain customers [27].

\section{E. Consideration variables in the pourchase of a smarphone device}

This section discusses consideration variables that influence users to purchase a smartphone device. The authors argue that because of the availability of smartphone devices on the market, users are free to choose a device they would like to purchase or use if it meets their needs, specifications, and requirements [28]. The authors further argue that the main consideration concerning smartphone devices and their influence on the users' social network is not only about accessing and exchanging information [1].

The main consideration is, however, the importance of the role that the smartphone device plays in changing the lives of users in their social networks [1]. There is a need to establish in this study the variables that may influence users' decision to purchase a smartphone device in their social networks.

The authors present the following perceived variables as influential in the purchase of smartphone devices in the users' social network, namely, friends, TV or web adverts, online adverts, mobile network and service providers, social media platforms, print media adverts, websites, as well as the Internet [24]. Little is known in the literature about the variables that affect users' decision to choose, purchase and use a mobile device.

\section{THEORETICAL FRAMEWORK}

After discussing the literature review, this section discusses the theoretical framework of the study. This study uses the social shaping of technology (SST) as a theoretical framework to guide this study. The authors argue that the social shaping of technology theory has been used in similar studies to guide issues about user perceptions of mobile devices, their usage, as well as their impact in shaping the lives of users in societies [9].

Providing a brief context about the theory, the SST seeks to identify spaces and situations, where socio-technical changes can be evaluated, addressed, and politicised [13]. The theory also allows users and institutions to undergo varying degrees of mobilisation, displacement, and reconfiguration as an integral element of socio-technical changes [2].

The SST theory does not only emphasise the attribution of societal factors; however, the theory rests upon the attribution of rather well-delineated, unchanging properties of technology itself [2]. The SST theory further refers to socio-technological issues on how these are negotiated as well as how these are resolved in the social context [5]. There is a need to evaluate relations between society and technology with a strong focus on the users' choices, strategies, and sociotechnological operations/learning, as well as adjustment of the research process [2].

The SST theory presents a varying degree of sociotechnological aspects to be analysed from various perspectives 
such as design, planning, implementation, or use of technology [13]. As such, the degree of influence on technology change depends on particular relations between various users of the social network and engagement with technologies [2]. Therefore, the users' visions, strategies and resources play a key role in shaping the dynamics of the societal ecosystem as a result of such interactions [2].

Also, the theory is further used to guide studies where technologies and societal impacts are co-shaped by innovation and application [9]. Also, the SST theory is used in studies that investigate ways in which economic, social, and institutional factors have shaped the use of technology, its direction, as well as the result of technology use in societies [20].

The study evaluates the users' perceptions about their decision to use, choose, and purchase a smartphone device in their social networks. Smartphone devices are sold to consumers like any other products [24]. With the fast and moving pace of technology, there is a need to maintain a strong relationship between manufacturers or service providers and users of smartphone devices [20].

Also, the authors claim that users are quick to perceive the benefits and shared values of using or purchasing a smartphone device [24].

Supporting the study's theoretical framework, the perceived benefits of smartphone devices may have an influence on users from the same social networks [20]. These perceived benefits could be considered as positive outcomes about the adoption and use of smartphone devices in the users' social network [11].

Also, the authors explain that the perceived benefits of smartphone devices' use in the social network of users have demonstrated that they influence the lives of users [11]. What has not been investigated in the literature is the extent of the influence about the perceptions of users from the same social network concerning the decision to use, choose, and purchase a smartphone device.

The SST theory is also used in similar studies where the following factors have been predominant [13]:

- Attention to choosing the emergence of stability in society.

- An apparent presence or absence of choice is taking place; and

- $\quad$ TThe natural flexibility of technology is taking place.

Users are free to decide on whether to use or not to use a smartphone product. Also, they explain that users are free to decide on whether to associate themselves with a particular service provider or mobile device manufacturer [10]. Users of smartphone devices have many options to choose from when it comes to using or purchasing a smartphone device [2].
Also, users of smartphone devices have many options to choose from when it comes to the service contract and offerings [2]. The author further explains that although users of smartphone devices have many options to choose from, such as the use, choice, and purchase of smartphone services including the service offerings, users are still very much influenced by the perceived benefits and shared values of devices as observed in their social networks [2].

With the aim of this study to evaluate the users' perceptions about their decision to use, choose, and purchase a smartphone device in their social networks, this study considers the following variables [5] and [13], namely:

- Technological determinism represented by technological social changes.

- Social and economic determinism represented by the social and economic contexts with direct development and use of technology.

- Technological and social changes because of dynamic interplays among inventions, social, economic, and political institutions, as well as a culture that takes place in the environment or social network of the user.

The adapted diagram representing the three constructs discussed in this section is found below [5] and [13].

\section{Social Shaping of Technology}

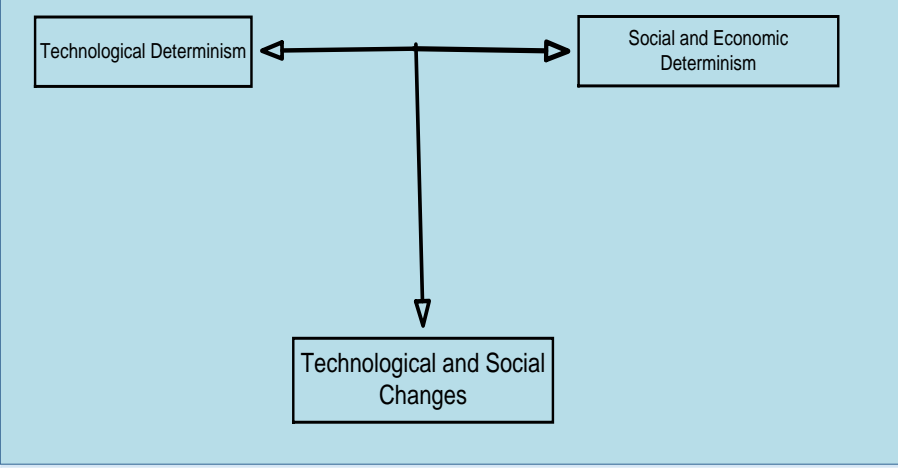

Fig 1. Social Shaping of Technology adapted from [5] and [13]

Mobile technologies are not neutral in themselves and the most important consideration is the way societies choose to use them [26]. The authors further explain that, depending on the purpose of the designed technology, this may influence access to certain social and cultural behaviours [26].

Using the three constructs of the SST theory, some technologies are more compatible with some social relations than with others in given social circumstances [26]. This study 
evaluates the users' perceptions about their decision to use, choose, and purchase a smartphone device in their social networks.

There seems to be an agreement regarding the social networks of users and the role of social factors in the creation of a community consensus, and this seems at first glance overwhelmingly formal and logical [25]. The rationale invoked in the sections of the literature makes use of the theoretical framework to investigate variables that affect the users' decision to use, choose, and purchase a smartphone device in their social networks.

\section{RESEARCH METHODOLOGY}

This section discusses the research methodology. The study uses a single methodological approach. A research methodology is a plan to determine the nature of the relationship between variables [8]. Following the quantitative approach, the approach is relatively independent of the context and uses objective techniques such as numeric data and standardised measures [3]. The quantitative approach is advantageous because of the following [23]:

- Focuses on numerical data.

- Mainly uses a positivism paradigm.

- Is embedded in a highly controlled experimental setting, thus scientific.

- Is mainly objective.

- Is deductive in nature.

- Generates generalizable data; and

- Is outcome-oriented.

While the quantitative approach presents advantages, the approach also presents limitations [15]. For this study, a standard research instrument in the form of a questionnaire was used. A questionnaire is defined as a set of questions that must be answered by participants in a research project [3].

This study uses a survey to collect data from participants. Surveys in quantitative studies are easy to analyse since they can be applied to a large population [15]. In addition, the authors claim that the quantitative approach can generalise accurate outcomes [15]. Surveys when properly used can generate reliable results and valid measurements [19]. Quantitative analysis also provides the ability to make inferences on participants' characteristics and attitudes, as well as on their behaviours [8].

The study followed a descriptive-explanatory philosophy associated with the quantitative research method where data were synthesised and analysed. Conclusions were then drawn from the descriptive data. With a young adult population estimated at more than two hundred and fifty thousand in the Durban central area, according to Statistics South Africa (Stats SA), the study targeted young adults, male and female, employed and unemployed, as well as students, below the age of 35 .
The study used probability sampling. Probability sampling can be defined as a technique in which every unit or group in the population target has a chance (that is, non-zero probability) of being selected in the sample [3]. The type of probability sampling used is stratified random sampling, in which each unit from within a group of young adults residing in the Durban central area had a chance to be selected.

Given the large population of young adults in the Durban area and the logistics associated with analysing a large population, the study targeted three hundred and twenty participants, and hundred and eighty-one were considered as the sample size. The study adopted the formula to calculate a representative sample, where $95 \%$ represents the confidence level needed, $\mathrm{K}=$ applicable value 1.96 and hundred and eighty-one estimated number of young adults residing in the Durban central area [8].

The research instrument was tested for reliability and accuracy of three respondents before being administered to the rest of the participants. The research instrument used the following scales, namely, nominal, binary, and Likert scales.

\section{DATA ANALYSIS AND DISCUSSION}

The following tests were used to analyse the findings, namely:

- Descriptive statistics including means and standard deviations, where applicable frequencies are represented in tables.

- Chi-Square goodness-of-fit-test: A univariate test used on a categorical variable to test whether any of the response options are selected significantly more or less often than the others. Under the null hypothesis, it is assumed that all responses are equally selected; and

- Binominal test to compare the observed frequencies of the two categories of a dichotomous variable to the frequencies that are expected under binomial distribution with a probability parameter used in this study for both groups is 0.5 . 


\section{A. Demographic characteristics}

TABLE I

\begin{tabular}{|c|c|c|}
\hline Gender & Frequency & $\%$ \\
\hline Male & 87 & $67.3 \%$ \\
\hline Female & 31 & $32.3 \%$ \\
\hline \multicolumn{3}{|l|}{ Age } \\
\hline $15-20$ & 55 & $57.1 \%$ \\
\hline $21-26$ & 23 & $26.2 \%$ \\
\hline Older than 27 & 12 & $16.7 \%$ \\
\hline \multicolumn{3}{|l|}{ Employment status } \\
\hline Student & 79 & $65.7 \%$ \\
\hline Employed & 23 & $21.8 \%$ \\
\hline Unemployed & 29 & $12.5 \%$ \\
\hline
\end{tabular}

The demographic characteristics indicated that $67.3 \%$ of respondents were male and $33.7 \%$ of respondents were female. The findings indicated that $57.1 \%$ of respondents were young adults aged between 15 and $20,26.2 \%$ of respondents were aged between 21 and 26, and $16.7 \%$ of respondents were older than 27. The demographic characteristics indicated that $65.7 \%$ of respondents were students, $21.8 \%$ were employed, and $12.5 \%$ were unemployed.

\section{B. Mobile device brand and service providers}

TABLE II

\begin{tabular}{|r|c|c|}
\hline Cell phones make & Frequency & $\%$ \\
\hline Samsung & 64 & $36.4 \%$ \\
\hline Huawei & 43 & $29.8 \%$ \\
\hline Apple iPhone & 21 & $19.8 \%$ \\
\hline Hisense & 8 & $10.0 \%$ \\
\hline Others & 1 & $3.0 \%$ \\
\hline Service providers & & \\
\hline Vodacom & 31 & $40.7 \%$ \\
\hline MTN & 23 & $35.4 \%$ \\
\hline Cell-C & 11 & $16.9 \%$ \\
\hline Others & 24 & $7.0 \%$ \\
\hline
\end{tabular}

The findings of the mobile device brand indicated that the Samsung cell phone brand was used by $36.4 \%$ of respondents, $29.8 \%$ of respondents used Huawei, $19.8 \%$ of respondents used Apple iPhone, $10.0 \%$ of respondents used
Hisense, and $3.0 \%$ of respondents used other cell phone brands or makes.

From the findings, it can be noted that Samsung was among the most-used brand among respondents in Durban, South Africa. The findings about the high proportion of Samsung brand usage could mean that users liked the interoperability and capabilities of the device to remain connected in the social network. The findings could also mean that respondents liked Samsung's ease of use.

The findings indicated that $40.7 \%$ of respondents used Vodacom as their service provider, $35.4 \%$ used MTN as their service provider, $16.9 \%$ used Cell $\mathrm{C}$, and $7.0 \%$ used other service providers. From the findings, it is important to note that Vodacom has many customers as compared to other service providers among users.

The findings could mean that users regard the quality of service as important from their service providers [7], [11] and [24]. The findings could also mean that users are still loyal to their network operator and still want to associate themselves with the network' service offerings.

\section{Users' social networking influence on the choice of mobile devices}

TABLE III

Users' social network influence on the choice of mobile devices

\begin{tabular}{|c|c|c|}
\hline $\begin{array}{c}\text { Social Network (SN) } \\
\text { influence on the } \\
\text { choice of a mobile } \\
\text { device }\end{array}$ & Cumulative & Percentage \\
\hline Yes & 126 & $69,6 \%$ \\
\hline No & 55 & $30.4 \%$ \\
\hline Total & 181 & 100 \\
\hline
\end{tabular}

The findings about the influence of the social network of users on the choice of mobile devices indicated that $69.6 \%$ of respondents agree that the social network influenced their choice of mobile devices, and $30.4 \%$ of respondents disagree that the social network influenced the choice of mobile devices.

The findings concerning the influence of the social network of users on the choice of mobile devices were an important development. The number of interactions and the need to remain connected in the social network were important parameters to consider in these findings. The findings support arguments discussed in the literature that technological, economic, political, and social factors, among others affect either opening or closing social options on the users' social networks [26].

Arguments in the literature support the hypothesis that technological devices such as mobile devices can influence the social networks of users, and, most importantly, users must decide about how they would like to use the technology [26]. 


\section{Use of mobile devices}

TABLE IV

Use of mobile devices.

\begin{tabular}{|c|c|c|c|c|}
\hline \multicolumn{2}{|r|}{ Mobile device use } & \multirow{2}{*}{$\begin{array}{c}\text { Frequency } \\
65\end{array}$} & \multicolumn{2}{|c|}{$\%$} \\
\hline \multirow{2}{*}{1} & \multirow{2}{*}{$\begin{array}{l}\text { To stay in touch } \\
\text { with friends and } \\
\text { family }\end{array}$} & & Yes & $53.8 \%$ \\
\hline & & 23 & No & $46.2 \%$ \\
\hline \multirow{2}{*}{2} & \multirow{2}{*}{$\begin{array}{l}\text { To browse Internet } \\
\text { and access social } \\
\text { network sites }\end{array}$} & 52 & Yes & $78.8 \%$ \\
\hline & & 14 & No & $21.2 \%$ \\
\hline \multirow{2}{*}{3} & \multirow{2}{*}{$\begin{array}{c}\text { To send and receive } \\
\text { emails }\end{array}$} & 36 & Yes & $59.2 \%$ \\
\hline & & 30 & No & $40.8 \%$ \\
\hline \multirow{2}{*}{4} & \multirow{2}{*}{$\begin{array}{c}\text { To text, chat, and } \\
\text { exchange } \\
\text { information }\end{array}$} & 60 & Yes & $57.5 \%$ \\
\hline & & 16 & No & $42.5 \%$ \\
\hline \multirow{2}{*}{5} & \multirow{2}{*}{$\begin{array}{c}\text { To use mobile } \\
\text { enabled } \\
\text { applications }\end{array}$} & 43 & Yes & $59.2 \%$ \\
\hline & & 23 & No & $40.8 \%$ \\
\hline \multirow{2}{*}{6} & \multirow{2}{*}{$\begin{array}{l}\text { To make and } \\
\text { receive calls }\end{array}$} & 62 & Yes & $56.7 \%$ \\
\hline & & 4 & No & $43.3 \%$ \\
\hline \multirow{2}{*}{7} & \multirow{2}{*}{$\begin{array}{l}\text { To make use of e- } \\
\text { services }\end{array}$} & 51 & Yes & $54.5 \%$ \\
\hline & & 15 & No & $45.5 \%$ \\
\hline \multirow{2}{*}{8} & \multirow{2}{*}{$\begin{array}{l}\text { To learn and search } \\
\text { for new meanings }\end{array}$} & 15 & Yes & $22.7 \%$ \\
\hline & & 51 & No & $77.3 \%$ \\
\hline
\end{tabular}

The findings indicated that the following were the most significant activities used on smartphone devices by users: $78.8 \%$ of respondents used their smartphone devices to browse the Internet and access social networking sites; $59.2 \%$ used their smartphone devices to access enabled-applications such as camera, video, clock, audio, calculator, navigator, calendar etc.; $59.2 \%$ used their smartphone devices to send and receive emails; $57.5 \%$ used their smartphone devices to text, chat, and exchange information; $56.7 \%$ of respondents used their smartphone devices to make and receive calls; $54.5 \%$ used their smartphone devices to make use of eservices such as payment, money transfer, shopping and placing orders online, etc.; and $53.8 \%$ of respondents used their smartphone devices to stay in touch with friends and family.

The findings support arguments discussed in the sections of this literature. The use of mobile devices has been extensively driven by the emergence of new generations of smart devices [27]. These smart devices are equipped with the capabilities to do more than one task at a time [27]. Concerning social determinism, users from the social network are shaped by several elements that determine the usage of devices predominantly to stay in touch with their peers from the same social networks, to access social networking sites, receive and send emails, text, or chat with other users from their social networks, and further engage in similar activities supported by technologies used in the same social network [5] and [13].

The findings further conclude with remarkable similarity in the way users engage with mobile technologies and, in this case, with smartphone devices. The findings further support arguments discussed in the literature explaining that the use of smartphone devices has ultimately increased the notion of sociability, reassurance, and human interaction [28].

\section{E. Frequency of smartphone devices'use}

1) Activities used by users on their smartphone devices daily.

The findings were compelling for respondents, who used the following activities on their smartphone devices every day in their social network:

- Instant messaging such as WhatsApp Messenger, Showmax-Watch TV, Likee, TikTok, Facebook Lite, SHARE it, Clicks, etc. $(\mathrm{Z}(\mathrm{N})=181)=2.215$, $\mathrm{p}<.0005)$.

- Social networking sites such as Facebook, YouTube, Instagram, Snapchat, Skype, Pinterest, Line, Twitter etc. $(\mathrm{Z}(\mathrm{N})=181)=4.523$, $\mathrm{p}<.0005)$.

2) Activities used by users on their smarphone devices every week.

The findings were compelling for users, who used the following activities on their smartphone devices every week in their social network:

- Blogs and microblogs such as Twitter, Tumblr, Blogger, Yammer, Pinterest, etc. $(\mathrm{Z}(\mathrm{N})=181)$ $=3.908, \mathrm{p}<.0005$ ).

- $\quad$ Texting messages/SMS/MMS, as well as making and receiving calls $(\mathrm{Z}(\mathrm{N})=181)=1.631, \mathrm{p}<.0005)$.

- Mobile-enabled applications such as calculator, alarm, camera, video, game, clock, calendar, audio, $\mathrm{FM}$ radio stations, etc. $(\mathrm{Z}(\mathrm{N})=181)=2.723$, $\mathrm{p}<.0005)$.

3) Activities used by users on their smarphone devices less than once a month.

The findings were significant for users, who used the following activities on their smartphone devices less than once a month in their social network:

- Collaborative and document sharing such as Wiki, Microsoft SharePoint, Google Docs etc. $(\mathrm{Z}(\mathrm{N})=181)$ $=3.815, \mathrm{p}<.0005)$.

- Content communities such as YouTube, Flickr, Digg, Picassa, etc. $(\mathrm{Z}(\mathrm{N})=181)=3.954, \mathrm{p}<.0005)$. 


\section{General comments}

The findings about the frequency of smartphone devices' use link to the previous section on the usage of mobile devices. The predominance of social networking sites and microblogs used seamlessly on various smart devices has increased the notion of sociability, as well as human interaction.

The manner in which users from the social network decide to use, choose, and purchase a smartphone device provides new options of influence on users from the same social network. The findings have also revealed that human interaction, because of social determinism, has been significantly consistent throughout the environment or technological platform used by users of the same social networks.

\section{F. Factors influencing the decision to buy a mobile device in the social network of users}

The following were the most significant factors influencing the decision of users to buy a mobile device in the social network:

1) Buy a mobile device because they saw the advert on $T V$, on the Internet, or in a magazine or newspaper.

The findings indicated that $18.2 \%$ of users strongly disagree with the statement, $27.3 \%$ of them disagree with it, $16.7 \%$ neither agree nor disagree, $31.8 \%$ agree, and $6.1 \%$ strongly agree.

The findings indicated that the results were enough to conclude that the level of agreement was important in the social network of users when considering buying a mobile device because the users saw the advert on TV, on the Internet, or in magazine or newspaper $(\mathrm{Z}(\mathrm{N})=181)=3.954$, $\mathrm{p}<.0005)$.

\section{2) Buy because they like the mobile device}

The findings indicated that $6.1 \%$ of users strongly disagree with the statement, $6.1 \%$ of them disagree with it, $12.1 \%$ neither agree nor disagree, $40.9 \%$ agree, and $40.9 \%$ strongly agree.

The findings indicated that the results were enough to conclude that the level of agreement was important in the social network of users when considering buying a mobile device because the users liked the mobile device $(\mathrm{Z}(\mathrm{N})=181)$ $=3.954, \mathrm{p}<.0005$ ).

3) Buy because of the applications and features on the mobile device.

The findings indicated that $6.1 \%$ of users strongly disagree with the statement, $3.0 \%$ of them disagree with it, 9.1\% neither agree nor disagree, $37.9 \%$ agree, and $43.9 \%$ strongly agree.

The findings indicated that the results were significant to conclude that the level of agreement was important in the social network of users when considering buying a mobile device because of its built-in applications and features $(\mathrm{Z}(\mathrm{N})$ $=181)=3.954, \mathrm{p}<.0005$ ).

4) Buy because of the quality of the mobile device.

The findings indicated that $3.0 \%$ of users strongly disagree with the statement, $10.6 \%$ of them disagree with the statement, $7.6 \%$ neither agree nor disagree, $30.3 \%$ agree, and $48.5 \%$ strongly agree.

The findings indicated that the results were significant to conclude that the level of agreement was important in the social network of users when considering buying a mobile device because of its quality $(\mathrm{Z}(\mathrm{N})=181)$ $=4.200, \mathrm{p}<.0005$ ).

5) Buy because of the quality of service provided by the network provider.

The findings indicated that $6.1 \%$ of users strongly disagree with the statement, $15.2 \%$ of them disagree with it, $30.3 \%$ neither agree nor disagree, $19.7 \%$ agree, and $28.8 \%$ strongly agree.

The findings indicated that the results were significant to conclude that the level of agreement was important in the social network of users when considering buying a mobile device because of the quality of service provided by the network provider $(\mathrm{Z}(\mathrm{N})=181)=3.969$, $\mathrm{p}<.0005)$.

6) Buy because the user is loyal to the network provider.

The findings indicated that $28.8 \%$ of users strongly disagree with the statement, $21.2 \%$ of them disagree with it, $25.8 \%$ neither agree nor disagree, $16.7 \%$ agree, and $7.6 \%$ strongly agree.

The findings indicated that the results were significant to conclude that the level of agreement was important in the social network of users when considering buying a mobile device because of the users' loyalty to the service provider $(\mathrm{Z}(\mathrm{N})=181)=2.631, \mathrm{p}<.0005)$.

7) Buy because the user is loyal to the mobile device manufacturer.

The findings indicated that $34.8 \%$ of users strongly disagree with the statement, $22.7 \%$ of them disagree with it, $21.2 \%$ neither agree nor disagree, $10,6 \%$ agree, and 10,6\% strongly agree.

The findings indicated that the results were significant to conclude that the level of agreement was important in the social network of users when considering buying a mobile device because of the users' loyalty to the mobile device manufacturer $(\mathrm{Z}(\mathrm{N})=181)=2.446, \mathrm{p}<.0005)$.

8) Buy because the mobile device is affordable.

The findings indicated that $1.5 \%$ of users strongly disagree with the statement, $12.1 \%$ of them disagree with it, $12.1 \%$ neither agree nor disagree, $25.8 \%$ agree, and $48.5 \%$ strongly agree. 
The findings indicated that the results were significant to conclude that the level of agreement was important in the social network of users when considering buying a mobile device because of its affordability $(\mathrm{Z}(\mathrm{N})=181)=3.969$, $\mathrm{p}<.0005)$.

\section{General comments:}

The findings about the factors influencing the decision to buy a mobile device in the social network of users were discussed in the section of the literature. The findings revealed that factors such as adverts, the Internet, magazines, the use of mobile devices, the design and purpose of a mobile device, the loyalty of customers to service providers and technology or device manufacturers, as well as the affordability of devices, were significant in influencing the decision of users from the social networks to use, choose, and purchase a mobile device.

The findings further support arguments in the literature explaining that the decision of users to use, choose, and purchase a mobile device can be influenced by the type of services, the quality of services, as well as the loyalty of users to a smartphone manufacturer or network service provider [20].

For the same reason, service providers and mobile device or brand manufacturers in the process of design, intentionally or unintentionally and regardless of the purpose of the technology, are optimistic that the technology can influence users from the same social network and could further influence or shape the way they use it. The authors suggest making use of the social vacuum purposefully given the effect of the technology in the lives of users from the social networks [7].

\section{CONCLUSION}

The study assessed the main factors that influence the decision of users from social networks to use, choose, and purchase a mobile device. The research analyses provided an important insight into the way users make their decisions to use, choose, and purchase a mobile device. In the section of the literature, it was indicated how the effect of the technological, economic, environmental, and societal factors could change the way users decide to use technology. In this regard, the authors explain that technologies were not neutral in themselves and users had to play their part in the way they decide to use them [26].

Technological factors and the advent of social networking sites have revealed that their influence was enough in increasing human interaction, which had a role to play in the manner in which users from the social network decide to communicate and remain constantly connected. The findings further revealed that the notion of sociability and human interaction was well supported in the users' social networks by either one or a combination of technological, environmental, economic, or societal determinism factors.
The research findings provided a strong indication of what youngest adults in their social networks considered as important activities on their mobile devices. The findings indicated that there was a strong indication of increased human interaction, the notion of sociability and the need to remain always connected. The research findings also revealed consistency in activities and their frequency among users of the same social network because of being connected and shaped using mobile devices.

As indicated in the section of the literature, technological aspects, or determinism factors such as interoperability of devices and augmented capabilities or features found on smartest devices used by young adults in their social networks have played a key role in shaping the lives of many users concerning the manner they decide to use, choose, and purchase their mobile devices.

The findings about the forces influencing the decision of users to use, choose, and purchase a mobile device, were a great contribution to the study. In a social environment, the analyses indicated that the accuracy, appropriateness of technological media, and marketing strategies used by service and network providers to retain or attract users from the social networks need to be well-designed to make use of the social vacuum given the effect of technologies in the hands of users.

\section{REFERENCES}

[1] Albane, A., Hampshire, K., Mashiri, M., Munthali, A., Porter, G. \& Tanle, A. (2012). Youth, mobility, and mobile phones in Africa: Findings from a threecountry study, Information Technology for Development. Information Technology for Development, 18(2), 145-162.

[2] Ayal, A. (2011). Freedom of Choice: Lessons from the Cell Phone Market. Laws and Contemporary Problems, 74(91).

[3] Bhattacherjee, A. (2012). Social Science Research: Principles, Methods and Practices $\left(2^{\text {nd }} E d.\right)$. Florida. Jacobs Foundation.

[4] Bijker, W.E. (1995). Of Bicycles, Bakerlites, and Bulbs: Toward a Theory of Sociotechnical Change. Cambridge, Massachusetts, The MIT Press.

[5] Birke, D. \& Swann, P. (2010). Network Effects, Network Structure Consumer Interaction in

Mobile Telecommunication in Europe and Asia. Journal of Economics Behavior \& Organization, 76(10), 152-167.

[6] Boateng, R. \& Duncombe, R. (2009). Mobile phones and financial services in developing 
countries: A review of concepts, methods, issues, evidence, and future research directions. Third World Quarterly, 30(7), 1237-1258.

[7] Bode, W.F., Franks, D.W. \& Wood, A.J. (2012). Social networks improve leaderless group navigation by facilitating long-distance communication. Current Zoology, 58(2), 329-341

[8] Bougie \& Sekaran, U. (2010). Research Methods for Business: A Skill Building Approach (5th Ed.). Chichester: Wiley.

[9] Brown, R. \& Mercer, D. (2009). The Social Shaping of Technology: Lessons for Eco Innovators. Australian Journal of Information Systems, 16.

[10] Cao, X., Gu, J., Guo, X., Liu, H. (2015). The role of social media in supporting knowledge integration: A Social capital analysis. Information Systems Frontiers, 17(2), 351-362.

[11] Dauda, Y.S. \& Lee, J. (2014). A conjoint analysis of consumers' preferences on future online banking services. Information Systems, Volume 53, Pages 1-15.

[12] Davis, R., Laszlo, S. \& Chandhri, A. (2011). Do Consumers Trust Mobile Service Advertising? Contemporary Management Research, 7(4), 245-270.

[13] Edge, D. \& William, R. (1996). The social shaping of technology. Research Policy, 25(1996), 865-899.

[14] Feng, X. \& Zhu, A. (2010). A Social Network Solution Based on Mobile Subscriber Contact-Books. Bell Labs Technical, 15(1), 53-66.

[15] Frels, L. \& Onwuegbuzie, H. (2013). Demystifying Mixed Methods Research Design: A Review of the Literature. Melvana International Journal of Education (MIJE). Vol.3 (2), pp.112-122.

[16] Garcia, E., Hoveyda, P. K \& Melanie, Z. (2012). South African Mobile Generation: Study on South African Young People. Digital Citizen Safety.

[17] Gladerev, B. \& Markku, L. (2008). Social networks and cell phone use in Russia: local consequences of global communication technology. New Media Society, 10(273).

[18] Gunopulos, D., Kotzias, D. \& Lappas, T. (2016). Home is where you are friends: Utilizing the social graph to locate twitter users in a city. Information Systems, Volume 57, Pages 111-128.

[19] Ibrahim, M.A. (2012). Thematic Analysis: A Critical review of its Process and Evaluation.

Academic conference proceedings. WEI International European.

[20] Jorgensen, M. S. \& Jorgensen, U. (2009). Green Technology Foresight of High Technology: A Social Shaping of Technology Approach to the analysis of hopes and hypes. Technology Analysis \& Strategic Management, 21(3), 363-379.

[21] Kalkbreaner, J. \& McCampbell, A. (2011). The Advent of Smartphones: A study on the effect of handheld electronics on personal and professional productivity. Journal of Applied Global Research, $8(2011)$

[22] Levy, D. M., Nardick, D.L., McWatters, L. \& Turner, J. W. (2011). No Cell phone? No Internet? So Much Less Stress. Chronicle of Higher Education, 57(36).

[23] Lewis, P., Saunders, M. \& Thornhill, A. (2009). Research Methods for Business Students (5th ed.): Pitman Publishing Imprint.

[24] Lu, Y. \& Zhoo, T. (2011). Examining Post adoption of Mobile Services from a Dual Perspective of Enablers and Inhibitors. International Journal of Human-Computer Interaction, 27(12), 1177-1191.

[25] Mackenzie, D. (1996). Knowing Machines: Essays on Technical Change. Cambridge, Massachusetts: MIT Press.

[26] Mackenzie, D. \& Majcman, J. eds. (1999). The Social Shaping of Technology, $2^{\text {nd }}$ ed., Open University Press, Buckingham, UK.

[27] Molapo, M. E. \& Mukwada, G. (2011). The Impact of Customer Retention Strategies in the South African Cellular Industry: The Case of Eastern Free State. International Journal of Business, Humanities and Technologies, 1(2).

[28] Ngai, W.T., Moon, K., Spencer, S. \& Tao, C. (2015). Social media research: Theories, constructs, and conceptual frameworks. International Journal of Information Management, 35(1), 33-44.

[29] Statssa (see Statistics South Africa). Retrieved from http://www.statssa.gov/?page $\mathrm{id}=4286 \& \mathrm{id}=10350$. Accessed on 2016-12-03. 